American Journal of Pharmacology and Toxicology 2 (2): 46-50, 2007

ISSN 1557-4962

(C) 2007 Science Publications

\title{
In Vivo Anti-malarial Tests of Nigella sativa (Black Seed) Different Extracts
}

\author{
Abdulelah, H.A.A. and Zainal-Abidin, B. A. H. \\ School of Biosciences and Biotechnology, Faculty of Science and Technology \\ National University of Malaysia, 43600 UKM Bangi, Selangor, Malaysia
}

\begin{abstract}
Nigella sativa (black seed) seeds have been used as a traditional medicine for the treatment of a variety of sicknesses including parasitic diseases. Intraperitoneal and oral administrations of ethanol, chloroform and aqueous seed extracts $\left(50,100,200\right.$ and $\left.400 \mu \mathrm{L} \mathrm{kg}^{-1}\right)$ of $N$. sativa, were screened in the 4-day suppressive assays for their anti-malarial properties against Plasmodium berghei in mice. Both intraperitoneal and oral treatments of the seeds extracts showed suppression activities in all groups of mice with the highest values were noted by the 100 and $200 \mu \mathrm{L} \mathrm{kg}^{-1}$ doses of the ethanol extract and by the $100 \mu \mathrm{L} \mathrm{kg}^{-1}$ dose of the chloroform extract which significantly $(\mathrm{p}<0.05)$ decreased the parasitaemias and increased the survival times of the infected mice. On the other hand, the aqueous extract showed a dose-dependent suppression activity by which the 200 and $400 \mu \mathrm{L} \mathrm{kg}^{-1}$ extracts doses showed significant degrees of suppression activities in the infected mice. The results of this study confirm the usage of this plant in the Middle East folk medicine as parasitic remedy and open a new opportunity to further investigate the potentials of new plant-based antimalarials in the future. However, the active responsible principles are yet to be identified, which need further studies to elucidate the anti-malarial mechanism of their action.
\end{abstract}

Keywords: Anti-malarial activity, Plasmodium berghei, Nigella sativa

\section{INTRODUCTION}

Malaria, a tropical disease caused by protozoan parasites of the genus Plasmodium is one of the most important infectious diseases in the world ${ }^{[1] . ~ M a l a r i a ~}$ kills over a million people each year, with as many as 300-500 millions people being infected, with extremely high fatality rates among young children below 5 years of age ${ }^{[2]}$. Furthermore, as anti-malarial drug resistance has become as one of the greatest challenges against malaria control, drug- resistance to chloroquine and more recently quinine ${ }^{[3]}$ was responsible in the spread of malaria to new areas and recurrence of malaria in areas where the disease has been eradicated. Drug resistance has also played an important role in the occurrence and severity of epidemics in some parts of the world. Population migration has introduced resistant parasites to areas previously free of drug resistance ${ }^{[4-5]}$. Moreover, reports also showed that more than $5 \%$ of 65 isolates of the parasite from South East Asia are resistant to artemisinin and artesunate ${ }^{[6]}$. Due to the increasing incidences of resistance to anti-malarial agents there is a need to develop more effective new anti-malarial drugs $^{[7]}$ that are inexpensive, routinely available to people especially those in the developing countries and the curative course must be short ${ }^{[8]}$. In this respect, traditional medicine, particularly plantbased anti-malarial products are more preferred simply because of their wide availability throughout the world. Artemisinine is one of the examples by which plantbased anti-malarials is produced.

The anti-malarial properties of many types of herbal or traditional plants have been recognized worldwide. In tropical countries including Malaysia many plants were recognized for their traditional values to cure many illnesses including malaria. Four quassinoids from Eurycoma longifolia Jack (which is commonly known as Tongkat Ali in Malaysia), eurycomanone, 13, 21-dihydroeurycomanone, $13 \alpha$ (21)-epoxyeurycomanone, eurycomalactone and an alkaloid, 9-methoxycanthin-6-one, displayed higher anti-malarial activity against Plasmodium falciparum Gombak A isolate when compared with chloroquine ${ }^{[9]}$. Recently, the potent anti-malarial agents, raphidecurperoxin and polysyphorin, were isolated from the Vietnamese medicinal plants, Rhaphidophora decursiva ${ }^{[10]}$. These plants products showed strong antimalarial activities without any toxicity effects.

The $N$. sativa seeds have a great medicinal importance and known to include many medicinal
Corresponding Author:

Abdulelah, H.A.A., School of Biosciences and Biotechnology, Faculty of Science and Technology, National University of Malaysia (Universiti Kebangsaan Malaysia), 43600 UKM Bangi, Selangor, Malaysia 
properties particularly in Greco-Arab/Unani-Tibb and Ayurveda system of medicine ${ }^{[11-14]}$. Recently, the seeds have been reported to exhibit many pharmacological effects including anti-parasitic (anti-helminthes ${ }^{[15]}$, anticestoda $^{[16]}$ and anti-schistosomal ${ }^{[17]}$ ), anti-bacterial ${ }^{[18]}$, anti-fungal ${ }^{[19]}$, anti-viral ${ }^{[20]}$, anti-oxidant ${ }^{[21]}$, antiinflammatory ${ }^{[22]}$ activities and have been shown to enhance the $\mathrm{T}$ cell mediated immune response ${ }^{[23]}$. In spite of the large number of pharmacological studies carried out world wide on N.sativa seeds, there is a need to investigate its anti-malarial activity. This study is therefore aimed to find out if N.sativa seeds possess any anti-malarial activities against rodent malaria Plasmodium berghei PZZ1/00 strain in ICR mice.

\section{MATERIALS AND METHODS}

Nigella sativa seeds of Yemeni origin were purchased from an herbal shop in Sana'a, Yemen. Department of Botany, School of Biosciences and Biotechnology, Universiti Kebangsaan Malaysia (UKM) authenticated the seeds. The seeds were dried and crushed into coarse powder. Four hundred grams of the powder were extracted with ethanol $(95 \% \mathrm{v} / \mathrm{v})$ and Chloroform according to Rajkapoor et al. ${ }^{[24]}$. The extracts were filtered and the solvents were evaporated in vacuum with a rotatory evaporator that yielded a blackish-brown concentrates and kept at $40 \mathrm{C}$ prior to use. The extractive values $(\% \mathrm{w} / \mathrm{w})$ of the ethanol and chloroform dry extracts were $4.3 \%$ and $7.5 \%$, respectively. The crude extracts were dissolved in dimethyl sulphoxide (DMSO) and sterilized distilled water (1:10) and then serially diluted to the desired concentrations $\left(50,100,200,400 \mu \mathrm{L} \mathrm{kg}{ }^{-1}\right)$. The aqueous extract was prepared using the method described by Al-Ghamdi ${ }^{[22]}$. Briefly, a started dose of $12.5 \mathrm{~g}$ of N.sativa powder in $100 \mathrm{~mL}$ distilled water was prepared before each experiment. The extract was filtered and diluted with sterilized distilled water to the desired concentrations.

Parasite Plasmodium berghei PZZ1/00 strain was used and maintained by weekly passage of infected blood in mice. A total of 216 adult male ICR mice weighing 28-32 g, 8 weeks old, obtained from the Animal House, UKM, were used for this study. The animals were fed with standard mouse pellets and clean drinking water ad libitum. The animals were caged in groups of six and kept in the animal laboratory in the School of Biosciences and Biotechnology in accordance with the internationally accepted principles for laboratory animal use and cares as found in the European Union guidelines.
Parasitized erythrocytes were obtained from a donor-infected mouse by cardiac puncture in heparin and serially diluted with a sterile Alsever's solution and inoculated intraperitoneally with $0.1 \mathrm{~mL}$ suspension containing $1 \times 10^{6}$ parasitized erythrocytes. For convenience day of infection was referred as D0.

The blood schizonticidal activities of the seed extracts, chloroquine (diphosphate salt, SIGMA as standard drug for positive control) and normal saline $(0.85 \%$ as negative control), were assessed by the 4 -day suppressive test ${ }^{[25]}$. The male ICR mice were inoculated intraperitoneally with $0.1 \mathrm{~mL}$ suspension (containing $1 \times 10^{6}$ P. berghei PZZ1/00 strain) on D0 and after 2-4 hrs post-infection, the experimental groups were treated either intraperitoneally or orally with 50,100, 200 and $400 \mu \mathrm{L} \mathrm{kg}^{-1}$ doses of the ethanol, aqueous and chloroform extracts. The positive control group was treated with chloroquine diluted in distilled water (10 $\left.\mathrm{mg} \mathrm{kg}{ }^{-1}\right)$. All the treatments were repeated for the next three days (D1-D3). On the fourth day (D4), blood smears were prepared and stained with Giemsa and parasitaemias were determined by counting the parasitized red blood cells from at least 9000 red blood cells. The average percent suppression of parasitaemia was calculated according to Peters \& Robinson ${ }^{[25]}$ and the mean survival time (days) for each group was determined over a period of 20 days post-infection.

Data from infected, treated and control mice were analyzed statistically using Student's t-test or one-way ANOVA to indicate significant levels between groups.

\section{RESULTS AND DISCUSSION}

Anti-malarial activity of different doses of the ethanol, aqueous and chloroform extracts intraperitoneally administrated are summarized in Table 1. Both ethanol and chloroform extracts showed suppression activities in all groups of mice with the highest values were noted by the $100 \mu \mathrm{L} \mathrm{kg}^{-1}$ dose for the ethanol extract ( $70.59 \%$ suppression) and by the $100 \mu \mathrm{L} \mathrm{kg}^{-1}$ dose for the chloroform extracts $(68.24 \%$ suppression) which significantly $(p<0.05)$ decreased the parasitaemias and increased the survival times of the infected mice. On the other hand, the aqueous extract showed a dose-dependent suppression activity by which the $400 \mu \mathrm{L} \mathrm{kg}^{-1}$ extract dose showed significant degrees of suppression $(69.39 \%)$ in the infected mice.

The oral administration of N.sativa extracts caused slightly higher values of anti-malarial activities with a notable high degrees of suppression were showed by the $100 \mu \mathrm{L} \mathrm{kg}^{-1}$ dose of the ethanol extract $(86.19 \%$ suppression) followed by the $400 \mu \mathrm{L} \mathrm{kg}^{-1}$ of the 
Am. J. Pharm. \& Toxicol., 2 (2): 46-50, 2007

Table 1: Anti-malarial screening of the ethanol, aqueous and chloroform extracts of N.sativa seeds treated intraperitoneally against P. berghei in mice

\begin{tabular}{lllll}
\hline Extracts & Dose $\left(\mu \mathrm{Lg}^{-1}\right)$ & Mean Parasitemia \pm S.D. $\dagger$ & $\begin{array}{l}\text { Average } \\
\text { Suppression \% }\end{array}$ & $\begin{array}{l}\text { Mean survival time } \pm \text { S.D. } \\
\text { day } \dagger^{\dagger}\end{array}$ \\
\hline Ethanol & 50 & $1.75 \pm 0.88$ & 57.12 & $8.50 \pm 1.20$ \\
& 100 & $1.20 \pm 0.68^{*}$ & 70.59 & $9.7 \pm 3.40^{*}$ \\
& 200 & $1.70 \pm 1.50$ & 58.33 & $10.30 \pm 2.40$ \\
- ve Control & 400 & $1.80 \pm 1.70$ & 55.88 & $8.50 \pm 1.20$ \\
+ ve Control & $0.2 \mathrm{~mL}$ & $4.08 \pm 1.70$ & 00.00 & $16.00 \pm 3.20$ \\
Aqueous & $10 \mathrm{mg}$ & $0.00 \pm 0.00$ & 100 & $7.80 \pm 0.45$ \\
& 50 & $3.50 \pm 1.00$ & 18.22 & $8.60 \pm 2.07$ \\
& 100 & $3.10 \pm 2.56$ & 27.57 & $7.80 \pm 0.45$ \\
- ve Control & 200 & $2.88 \pm 1.41$ & 32.71 & $10.80 \pm 2.59 *$ \\
+ ve Control & 400 & $1.31 \pm 1.28^{*}$ & 69.39 & $7.20 \pm 0.45$ \\
Chloroform & $0.2 \mathrm{~mL}$ & $0.28 \pm 0.94$ & 00.00 & $15.67 \pm 4.84$ \\
& $10 \mathrm{mg}$ & $2.15 \pm 2.48$ & 100 & $9.00 \pm 2.62$ \\
& 50 & $1.35 \pm 1.74^{*}$ & 49.41 & $11.17 \pm 2.32^{*}$ \\
- ve Control & 100 & $2.75 \pm 1.55$ & 68.24 & $10.00 \pm 2.61$ \\
+ ve Control & 200 & $3.00 \pm 1.47$ & 35.29 & $8.00 \pm 1.41$ \\
& 400 & $4.25 \pm 1.38$ & 29.41 & $7.60 \pm 0.82$ \\
\end{tabular}

*Significantly different from the saline control group $(\mathrm{P}<0.05)$

$\dagger$ Results are mean count \pm S.D. $(\mathrm{n}=6)$

Table 2: Anti-malarial screening of the ethanol, aqueous and chloroform extracts of N.sativa seeds treated orally against P. berghei in mice

\begin{tabular}{lllll}
\hline Extracts & Dose $\left(\mu \mathrm{L} \mathrm{kg}^{-1}\right)$ & Mean Parasitemia \pm S.D. $\dagger$ & $\begin{array}{l}\text { Average } \\
\text { Suppression \% }\end{array}$ & $\begin{array}{l}\text { Mean survival time } \pm \text { S.D. } \\
\text { (day) } \dagger^{\dagger}\end{array}$ \\
\hline Ethanol & 50 & $1.77 \pm 0.94$ & 45.85 & $9.17 \pm 1.83$ \\
& 100 & $0.46 \pm 0.51^{*}$ & 86.19 & $11.67 \pm 2.25^{*}$ \\
& 200 & $1.33 \pm 0.84^{*}$ & 60.06 & $12.17 \pm 3.06^{*}$ \\
-ve Control & 400 & $1.67 \pm 1.46$ & 49.85 & $9.50 \pm 2.26$ \\
+ve Control & $0.2 \mathrm{~mL}$ & $3.33 \pm 2.07$ & 00.00 & $17.00 \pm 3.79$ \\
Aqueous & $10 \mathrm{mg}$ & $0.00 \pm 00$ & 100 & $8.67 \pm 2.16$ \\
& 50 & $3.41 \pm 1.99$ & 20.81 & $10.00 \pm 1.67^{*}$ \\
& 100 & $2.00 \pm 2.38$ & 51.46 & $10.33 \pm 1.75^{*}$ \\
-ve Control & 200 & $1.13 \pm 0.88^{*}$ & 72.57 & $11.00 \pm 2.19^{*}$ \\
+ve Control & 400 & $0.95 \pm 1.47^{*}$ & 76.94 & $8.00 \pm 0.63$ \\
Chloroform & $0.2 \mathrm{~mL}$ & $4.12 \pm 1.17$ & 00.00 & $15.50 \pm 5.05$ \\
& $10 \mathrm{mg}$ & $0.00 \pm 00$ & 100 & $8.50 \pm 0.84$ \\
& 50 & $1.88 \pm 1.67$ & 52.16 & $9.83 \pm 1.33^{*}$ \\
-ve Control & 100 & $1.30 \pm 2.02^{*}$ & 66.92 & $9.00 \pm 2.10$ \\
+ve Control & 200 & $2.00 \pm 1.91$ & 49.10 & $9.17 \pm 1.83$ \\
\hline * Signific & $2.23 \pm 2.46$ & 43.26 & $7.67 \pm 1.03$ \\
\hline
\end{tabular}

* Significantly different from the saline control group $(\mathrm{P}<0.05)$

$\dagger$ Results are mean count \pm S.D. $(\mathrm{n}=6)$

aqueous extract (76.94 \% suppression) and $100 \mu \mathrm{L} \mathrm{kg}^{-1}$ of the chloroform extracts (66.92\% suppression), respectively. These treated groups of mice also had longer survival time (ranged between $9.83 \pm 1.33$ days and $11.67 \pm 2.25$ days) as compared to the other groups of treated mice and all positive control mice always had more than 15.00 days of survival time (Table 2).

In this preliminary evaluation and screening of anti-malarial activity of different extracts of N.sativa seeds the results showed that each of the three extracts have some degree of anti-malarial activity against P.berghei infection in the mice. The results also showed that higher doses of the extracts not necessarily caused higher degree of suppression although in case of aqueous extracts the $400 \mu \mathrm{L} \mathrm{kg}^{-1}$ dose gave considerable degree of suppression when given both intraperitoneally and orally. Overall results showed that the oral treatments were more effective, i.e., caused higher degrees of suppression when compared with the intraperitoneal treatments.

The anti-malarial activities exhibited by those extracts were perhaps due to the possible presence of active compounds. The extracts of N.sativa seeds contained different classes of alkaloids ${ }^{[26-29]}$ that were 
believed to block protein synthesis in Plasmodium falciparum $^{[30]}$. N.sativa seeds also contain phenolic ${ }^{[31]}$. These molecules are well known for their diverse physiological properties, including among others, anticarcinogenic, anti-inflammatory and anti-parasitic ${ }^{[32]}$.

Other works have showed that N.sativa seeds have possessed potential immunomodulatory effects ${ }^{[23]}$, which as a consequence might give some impact on the host-parasite interrelationship ${ }^{[33]}$. Consistent with this concept, the different extracts and active ingredients of $N$. sativa seeds have been reported to exert antimicrobial activities, including anti-bacterial ${ }^{[18]}$, antifungal ${ }^{[19]}$, anti-helminthic ${ }^{[15-17]}$ and anti-viral ${ }^{[20]}$ effects. Some of these anti-microbial effects have been attributed to the immunomodulatory effects of $N$. sativa seed components ${ }^{[14]}$.

The anti-oxidant effect of the $N$. sativa oil and its components may represent another mechanism that contributes to its anti-malarial activity. N.sativa seeds components inhibit nitric oxide (NO) production in macrophages $^{[21]}$. NO is a potent intracellular parasitekilling mechanism in macrophages and macrophages are crucial in innate immune response. These inhibitory assist in providing a favourable environment to multiplication of intracellular parasite; however, the inhibition of one killing mechanisms can cause the up regulation of secondary mechanisms which the parasite cannot protect itself against ${ }^{[33]}$. The inhibition of NO production causes an increase in tryptophan degradation through indolamine deoxygenase induction in human peritoneal macrophages; this starves the parasite of an essential amino acid, leading to its death ${ }^{[34]}$. A further anti-inflammatory effect of aqueous extract of N.sativa were reported by Al-Ghamdi ${ }^{[22]}$ and has been found to be hepatoprotective when liver injury is induced in mice by carbon tetrachloride ${ }^{[35]}$. It has also been shown to help to protect against chromosomal aberrations induced as a results of Schistosoma mansoni infection. In addition, $N$. sativa might also afford protection in schistosomiasis by modulating the immune response and reducing inflammation ${ }^{[36]}$.

The anti-malarial activities of N.sativa seed extracts observed in this study could have resulted from a single or combined action of these mechanisms. However, the active responsible principles are yet to be identified, which need further studies to elucidate the anti-malarial mechanism of their action. In conclusion, the results of this study justify and confirm the usage of this plant in the Middle East folk medicine as parasitic remedy.

\section{ACKNOWLEDGEMENTS}

The authors wish to record their appreciation for the assistance and facilities provided by Universiti Kebangsaan Malaysia (UKM) in this study.

\section{REFERENCES}

1. Breman, J.G., 2001. The ears of the hippopotamus: manifestations, determinants and estimates of the malaria burden. Am. J. Tropical Med. Hygiene, 64: $1-11$.

2. WHO, 2005. The World Malaria Report from WHO and UNICEF. World Health Organisation, Geneva.

3. Cordell, G.A., C.K. Angerhofer and J.M. Pezzuto, 1994. Recent studies on cytotoxic, anti-HIV and anti-malarial agents from plants. Pure \& Appl. Chem., 66: 2283-2286.

4. Foster, S.D., 1991. Pricing, distribution and use of antimalarial drugs. Bulletin of the World Health Organization, 69: 349-363.

5. Ridley, R.G., 1997. Plasmodium: Drug discovery and development an industrial perspective. Expl. Parasitol., 87: 293-304.

6. Pickard, A.L., C. Wongsrichanalai, A. Purfield, D. Kamwendo, K. Emery and C. Zalewski, 2003. Resistance to antimalarials in Southeast Asia and genetic polymorphisms in $p f m d r 1$. Antimicrob Agents Chemother, 47: 2418-2423.

7. Ridley, R.G., 2002. Medical need, scientific opportunity and the drive for anti-malarial drugs. Nature, 415: 686-693.

8. Rosenthal, P.J., 2003. Antimalarial drug discovery: old and new approaches. The J. Expl. Biol., 206: 3735-3744.

9. Chan, K., C. Choo, N.R. Abdullah and Z. Ismail, 2004. Antiplasmodial studies of Eurycoma longifolia Jack using the lactate dehydrogenase assay of Plasmodium falciparum. J. Ethnopharmacol., 92: 223-227.

10. Zhang, H.J., P.A. Tamez, V.D. Hoang, G.T. Tan and N. van Hung, 2001. Anti-malarial compounds from Rhaphidophora decursiva. J. Natural Product, 64: 777-772.

11. Chopra, R.N., S.L. Nayar and I.C. Chopra, 1956. Glossary of Indian Medicinal Plants. CSIR, New Delhi, India, pp: 175.

12. Junemann, M., 1998. Three great healing herbs. Twin Laked WI7 Lotus Light Publications, pp: 45.

13. Goreja, W.G., 2003. Black Seed: Nature's Miracle Remedy. New York, NY7 Amazing Herbs Press. 
14. Salem, M.L., 2005. Immunomodulatory and therapeutic properties of the Nigella sativa $\mathrm{L}$. seed. Intl. Immunopharmacol., 5:1749-1770.

15. Agarwal, R., M.D. Kharya, R. Shrivastava, 1979. Antimicrobial and anthelmintic activities of the essential oil of Nigella sativa Linn. Indian J. Expl. Biol., 17: 1264-1265.

16. Akhtar, M.S. and S. Rifaat, 1991. Field trial of Saussurea lappa roots against nematodes and Nigella sativa seeds against cestodes in children. J. Pak. Med. Assoc., 41: 185-187.

17. Azza, M.M., M.M. Nadia and S.M. Sohair, 2005. Sativa seeds against Schistosoma mansoni different stages. Mem Inst Oswaldo Cruz, Rio de Janeiro, 100: 205-211.

18. Hanafy M.S, Hatem M.E. Studies on the antimicrobial activity of Nigella sativa seed (black cumin). J. Ethnopharmacol., 34: 275-278.

19. Zeinab, E.M, H.A. Farrag, M. EL-Fouly and S. ELTablawy, 2001. Inhibitory effect of gamma radiation and Nigella sativa seeds oil on growth, spore germination and toxin production of fungi Radiation. Physics and Chemistry, 60: 181-189.

20. Salem, M.L. and M.S. Hossain, 2000. Protective effect of black seed oil from Nigella sativa against murine cytomegalovirus infection. Intl. J. Immunopharmacol., 22: 729-740.

21. Mahmood, M.S., A.H. Gilani, A. Khwaja, A. Rashid and M K. Ashfaq, 2003. The in vitro effect of aqueous extract of Nigella sativa seeds on nitric oxide production. Phytother Res., 17: 921-924.

22. Al-Ghamdi, M.S., 2001. The anti-inflammatory, analgesic and antipyretic activity of Nigella sativa. J. Ethnopharmacol., 76: 45-48.

23. Haq, A., P.I. Lobo, M. Al-Tufail, N.R. Rama and S.T. Al-Sedairy, 1999. Immunomodulatory effect of Nigella sativa proteins fractionated by ion exchange chromatography. Intl. J. Immunopharmacol., 21: 283-295.

24. Rajkapoor, B., R. Anandan and B. Jayakar, 2002. Anti-ulcer effect of Nigella sativa Linn against gastric ulcers in rats. Current Sci., 82: 177-179.

25. Peters, W. and B.L. Robinson, 1992. The chemotherapy of rodent malaria XLVII: studies on pyronaridine and other Mannich base antimalarials. Ann. Trop. Med. Parasitol., 86: 455-465.
26. Ata-ur-Rehman, S. Malik, H. Cun-Hung and J. Clardy, 1985. Isolation and structure determination of nigellicine, a novel alkaloid from seeds of Nigella sativa. Tetrahedron Lett., 26: 2759-2762.

27. Atta-ur-Rehman and S. Malik, 1993. Nigellidine, a new indazole alkaloid from seeds of Nigella sativa. J. Res. Iinst., 36: 1993-1996.

28. Morikawa, T., F. Xu, Y. Kashima, H. Matsuda, K. Ninomiya and M. Yoshikawa, 2004. Novel dolabellane-type diterpene alkaloids with lipid metabolism promoting activities from the seeds of Nigella sativa. Organic Lett., 6: 869-872.

29. Morikawa, T., F. Xum, K. Ninomiya, H. Matsuda and M. Yoshikawa, 2004. Nigellamines A3, A4, $\mathrm{A} 5$ and $\mathrm{C}$, new dolabellane-type diterpene alkaloids, with lipid metabolism-promoting activities from the Egyptian medicinal food black cumin. Chem. Pharm. Bull. (Tokyo), 52: 494- 497.

30. Elford, B.C., 1986. L-glutamine influx in malaria; infected erythrocytes: A target for antimalarials. Parasitol. Today, 2: 309-312.

31. Nergiz, C. and S. Otles, 1993. Chemical composition of Nigella sativa L. seeds. Food Chem., 48: 259-261.

32. Ma, Q., K. Kinner., 2002. Chemoprevention by phenolic antioxidants. J. Biol. Chem., 277: 24772484.

33. Antony, P.J., L. Fyfe and H. Smith, 2005. Plant active components-a source for anti-parasitic agents. Trend in Parasitol., 21: 462-468.

34. Daubener, W., 1999. Interluekin-1 inhibit gamma interferon-induced bacteriostaisis in human uroepithelial cells. Infection and Immunity, 67: 5615-5620.

35. Turkdogan, M.K., Z. Agaoglu, Z. Yerner, R. Ekeroglu and H.A. Akkan, 2001. Avci M E. The role of antioxidant vitamins (C and E), selenium and Nigella sativa in the prevention of liver fibrosis and cirrhosis in rabbits: new hopes. DTW Dtsch Tierarztl Wochenschr, 108: 71-73.

36. Mahmoud, M.R., H.S. El-Abhar and S. Salh, 2002. The effect of Nigella sativa oil against the liver damage induced by Schistosoma mansoni infection in mice. J. Ethnopharmacol., 79: 1-11. 